\title{
Assessment of genetic diversity of Prangos fedtschenkoi (Apiaceae) and its conservation status based on ISSR markers
}

\author{
Feruza U. Mustafina*, Eun Hye Kim, Sung-Won Son, Orzimat T. Turginov ${ }^{1}$, \\ Kae Sun Chang and Kyung Choi \\ Korea National Arboretum (KNA), Pocheon 11186, Korea \\ ${ }^{1}$ Institute of Gene Pool of Plants and Animals of Uzbek Academy of Sciences (IGPA UzSc), Tashkent 100053, Republic of Uzbekistan
}

(Received 8 January 2017; Revised 5 February 2017; Accepted 3 March 2017)

\begin{abstract}
Prangos fedtschenkoi (Regel et Schmalh.) Korovin (Apiaceae) is an endemic species for mountainous Middle Asia, which is both a rare and useful plant. Organic extractions from this species are being used in pharmaceutics and cosmetology. In recent years, P. fedtschenkoi distribution area has considerably decreased, presumably, resulting from human activities such as agriculture, construction works, overgrazing and collection from wild for pharmaceutic purposes. Six populations were found in Uzbekistan and their genetic divergence and differentiation were studied with 10 inter-simple sequence repeat (ISSR) markers, selected out of 101. Totally 166 amplified ISSR fragments (loci) were revealed, of which 164 were polymorphic. Relatively moderate level of polymorphism was found at population level with polymorphic bands ranging from $27.71 \%$ to $47.59 \%$. Mean $P=39.05 \%, N_{\mathrm{a}}=1.40, N_{\mathrm{e}}=1.25$, S.I. $=0.21$, and $H_{\mathrm{e}}=0.14$ were revealed for all loci across six populations. AMOVA showed higher variation among populations (62\%) than within them (38\%). The Bayesian model determined 5 clusters, or genetic groups. The posteriori distribution of the Theta II estimator detected full model identifying high inbreeding, intensified by low gene flow $(\mathrm{Nm}=0.3954)$. Mantel test confined population 6 as distinct cluster corresponding to geographic remoteness $(\mathrm{R}=0.5137, \mathrm{p} \leq 0.005)$. Results were used as the bases for developing conserve measures to restore populations.
\end{abstract}

Keywords: Prangos fedtschenkoi, endangered, rare resource plant, genetic diversity and differentiation, conservation measures, ISSR molecular markers, population structure

In Central Asia, Apiaceae is represented by around 110 genera with over 458 species (Pimenov and Leonov, 1993; Kljuykov and Ukrainskaya, 2010). Certain genera have been studied extensively, due to their economic importance as ornamental plants, food items and spices. Little is known, however, regarding the most of those devoid of economic value, such as Prangos species. One of the first attempts to describe and organize the genus Prangos Lindl. was made by Herrnstadt and Heyn (1977), but not all Central Asian and Caucasian species were represented in their monograph. Later Pimenov and Tikhomirov (1983) devoted their works to some problematic aspects of Umbelliferae-Apoideae and reported about 37 species in the genus. Presently, this genus includes approximately 46 species. Among all Prangos representatives, only P. bucharica B. Fedtsch., P. pabularia Lindl. and P. trifida (Mill.) Herrnst. and Heyn are widely distributed. All of the remaining species are found around two centers, both in Tethyan floristic region: to the West (from Turkey to west Iran, including Syria and Lebanon) comprising the majority of species; and to the East (east Iran, Afghanistan and Central Asia) (Herrnstandt and Heyn, 1977; Şenol et al., 2011). Thirteen species of Prangos grow in Turkey (Herrnstadt and Heyn, 1977; Davis et al., 1988; Duman and Watson, 1999; Duman, 2000; Duran et al., 2005), 16 species are recorded in the Flora Iranica (Herrnstadt and Heyn, 1987), 14 species in the Flora of the USSR (Shishkin, 1950), 4 species in the Flora

\footnotetext{
*Author for correspondence: mustafinaferuza@yahoo.com, mustafinafu@korea.kr
} 
of Syria (Post, 1932), and 3 species in the Flora Europaea (Tutin, 1968). Four new species were described from Anatolia only during last two decades (Davis et al, 1988; Duman, 2000; Duran et al., 2005; Pimenov et al., 2005). Recently one new species, P. hulusii S. G. Şenol, H. Yildirim O. Seçman sp. nov. was reported by Şenol et al. (2011) from Turkey.

Prangos fedtschenkoi is a rare endemic species from mountainous Middle Asia (Shishkin, 1950) more common for the Pamir-Alay than Tien Shan. Several populations are met in Kyrgyz Republic and Tajikistan. But no data are available to date about their present distribution in these countries. Very few populations lately described for Uzbekistan, scattered in more or less continuous areas in central and south-east parts of the country and recently have been reported in the northern regions of the Chimgan Mountains which are peripheral to southern populations of the species. Some of the populations are considered as remnants of previously wide presented species, distributed within unequal and highly fragmented areas.

Significant decline of $P$. fedtschenkoi populations has resulted mainly from human activities such as agriculture, construction works, overgrazing and collection from wild for pharmaceutic purposes (CACILM, 2006; Limin, 2012), as there are no industrial plantations established for this resource plant. P. fedtschenkoi has lost habitat to agriculture, hence requires implementation of conservation activities as endangered species. In spite of its biological importance as edificator in biotic community and endemic plant, as well as economic importance as valuable resource plant of phytocoumarins, only limited information is available on the extent, distribution, and nature of genetic variability in $P$. fedtschenkoi. To our knowledge, this species has never undergone population genetic analysis using molecular markers. The present study aims to investigate the patterns and levels of genetic diversity and differentiation in natural populations of a rare and useful resource plant by using intersimple sequence repeat (ISSR) genetic markers and to provide basic data for in situ and/or ex situ conservation strategies, management, and restoration of the species.

ISSR technique is a polymerase chain reaction (PCR) based method, reported by Zietkiewicz et al. (1994), which involves amplification of DNA segments between two identical microsatellite repeat regions. The technique uses microsatellite primers usually of 16-25 bp long, of di-, tri- , tetra- or pentanucleotide repeats to target multiple genomic loci. The evaluation of genetic variability among individuals and populations of $P$. fedtschenkoi was encouraging, because many polymorphic loci were identified easily, in a relatively short time and at low expenses without any prior knowledge of the genome of the species under study.

Besides, assessment of this species according to the International Union for Conservation of Nature (IUCN) criteria based on field research and population genetic study is highly in demand as it allows applying scientifically stipulated conservation, restoration and reintroduction procedures for this species and until now comparatively low number of Central Asian species are estimated against IUCN criteria and none of Prangos genus.

\section{Materials and Methods}

\section{Study species}

Prangos fedtschenkoi (Regel et Schmalh.) Korovin (Apiaceae) is a perennial herb species with yellow flowers and obovate entire petals bent inside of corolla and incorporated into multiple umbels of $6-10 \mathrm{~cm}$ in diameter. This species belongs to the subfamily Apioidea - a well classified group within Apiaceae Lindl. P. fedtschenkoi is an important source of natural coumarin compositions. This organic composition extracted from different Prangos Lindl. species has been subject of several investigations during the past decades as it is used in pharmaceutical industry as a precursor reagent in the synthesis of a number of synthetic anticoagulant pharmaceuticals similar to dicoumarol and as aromatic enhancer in perfumes and fabric conditioners (Kuzmina, 1963; Kuznetsova and Belenovskaya, 1969).

This species distributes in Uzbekistan between two contrasting ecological zones: the xerothermic desert and the mesothermic mountain regions. The species grow on fine soil, gravel and rocky slopes, on dry riversides in foothills and low mountains between 200-1,000 m altitudes. Floristic composition of natural habitats of $P$. fedtschenkoi includes species of Ferula, Eremurus, Achillea, Astragalus, Hordeum, Amygdalus and others. Climatic conditions of this area are continental. Central part of the country (Jizzakh region) and north-east (Tashkent region) are characterized by dry, hot summers and mild winter, south part of the country (Surkhandarya and Kashkadarya regions) is also continental but subtropical in spots. The growth period starts early in spring when the soil is not frozen. Seeds distribute presumably by means of natural factors like wind and water, as well as animals and human. The wind dispersal of the fruits is increased by the development of the wing shape ribs as well as cork-like mericarp.

Field work and conservation status assessment

Literature on $P$. fedtschenkoi distribution and about 100-120 
herbarium specimens had been analyzed before field work. According to the published data and geo-referenced herbarium specimens, this species was well distributed in about 14 spots (Fig. 1B): Zeravshan range and Ziadin-Zirabulak mountains in Samarkand province (Pimenov et al., 23.05.1981, MHA); in Kashkadarya province; Hissar range, Baysun mountains in Surkhandarya province; Malguzar and Nuratau mountains in Jizzakh province (Pimenov, Kljuykov, 04.07.1991, MW) and in Tashkent province (Regel, 17.06.1880, LE) in Uzbekistan;

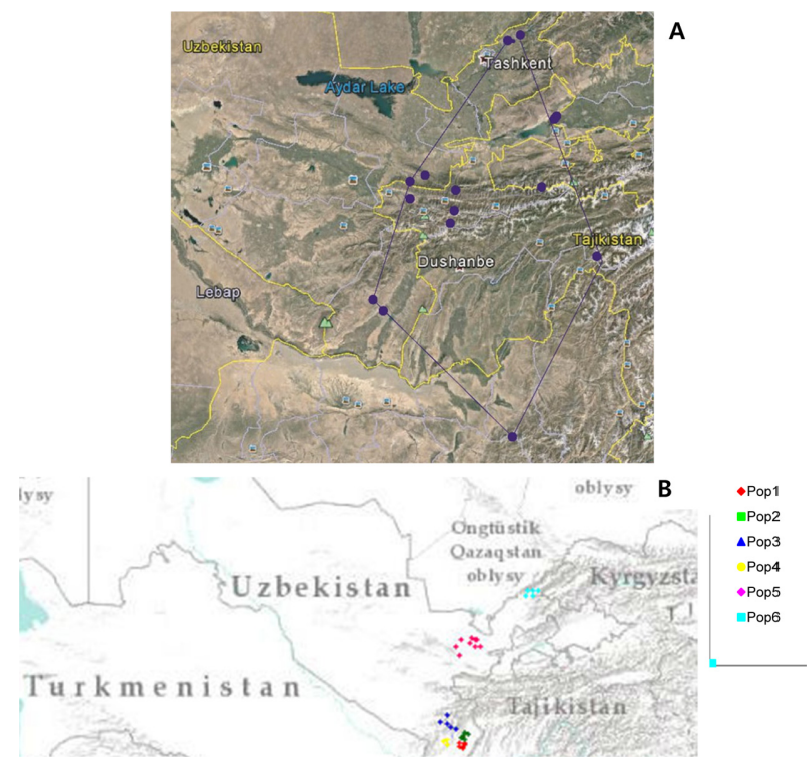

Fig. 1. A. The extent of occurrence of Prangos fedtschenkoi populations in Central Asia according to reference data. B. Location of P. fedtschenkoi populations in Uzbekistan. (Map source ArcGIS 10.3.1). over Pamir Alay Mountains: Alay Mount, Mogoltau in Tajikistan (Kuzmina, 19.05.1959, LE; Kuzmina. 01.08.1970, LE; Pimenov et al., 23.06.1988, MW); Turkestan, Alay ridge, Osh region in Kyrgyzstan (Baranova, 20.07.1981, MW) (Shishkin, 1950; Zakirov, 1961; Lyzkov, 2015). Field trips were conducted during 2014-2015 and totally six populations of $P$. fedtschenkoi were collected in Surkhandarya, Jizzakh and Tashkent regions (Fig. 1A, Table 1). It suggests that historically $P$. fedtschenkoi was widely distributed and sharply decreased over last decades. Conservation status of $P$. fedtschenkoi populations was analysed and visualized by using GeoCat Bridge 2.0 (2015): extension for Esri ArcGIS Desktop with use data of field work, literature data and herbarium material. GeoCat allows comparing the rate of referenced primary occurrence data to present geographic range of taxon: the extent of occurrence (EOO) and the area of occupancy (AOO) accordingly. IUCN category estimated according to IUCN red list categories and criteria (version 3.1, second edition, 2012).

\section{Sampling}

We sampled from size populations that cover the extent of the range (Table 1). Voucher specimens of all populations sampled were deposited at the Tashkent Central Herbarium (TASH). Fresh leaves of $P$. fedtschenkoi were collected from the middle part of healthy individuals that were separated from each other for about 2-3 m. Total of 60 individuals were sampled from six populations from different areas in Uzbekistan; ten individuals from each population were randomly collected. First five populations (Pop 1-5) were distributed in typical habitat for P. fedtschenkoi and were

Table 1. Collected samples of Prangos fedtschenkoi populations in Uzbekistan.

\begin{tabular}{|c|c|c|c|c|c|c|}
\hline No. & Populations & Coordinates & $\begin{array}{l}\text { Elevation } \\
\text { (m a.s.l.) }\end{array}$ & $\begin{array}{l}\text { Pop area } \\
\left(\mathrm{m}^{2}\right)\end{array}$ & $\begin{array}{l}\text { Pop.size/ } \\
\text { sample size }\end{array}$ & $\begin{array}{c}\text { Pop density } \\
\quad \text { (no. of } \\
\text { individuals } / \mathrm{m}^{2} \text { ) }\end{array}$ \\
\hline Pop 1 & $\begin{array}{l}\text { Kizil Naursay village, Left bank of Machay river, } \\
\text { Baysun region, Surkhandarya province. }\end{array}$ & $\begin{array}{l}\text { N38.2092882 } \\
\text { E67.2443603 }\end{array}$ & 865 & 20 & $25 / 10$ & 1.25 \\
\hline Pop 2 & $\begin{array}{l}\text { Kizil Naursay village, Baysun region, } \\
\text { Surkhandarya province. }\end{array}$ & $\begin{array}{l}\text { N38.2093161 } \\
\text { E67.2463478 }\end{array}$ & 216 & 20 & $25 / 10$ & 1.25 \\
\hline Pop 3 & $\begin{array}{c}\text { Fir forest, Kizil Naursay village, } \\
\text { Basin of Machay river, Baysun region, } \\
\text { Surkhandarya province. }\end{array}$ & $\begin{array}{l}\text { N38.2094841 } \\
\text { E67.2463278 }\end{array}$ & 216 & $30-40$ & $20 / 10$ & 0.5 \\
\hline Pop 4 & $\begin{array}{c}\text { Steppe, Kizil Naursay village, } \\
\text { Basin of Machay, Baysun region, } \\
\text { Surkhandarya province. }\end{array}$ & $\begin{array}{l}\text { N38.2095241 } \\
\text { E67.2461238 }\end{array}$ & 216 & $30-40$ & $25 / 10$ & 0.62 \\
\hline Pop 5 & $\begin{array}{l}\text { Turkestan range, Zaamin region, } \\
\text { Jizzakh province. }\end{array}$ & $\begin{array}{l}\text { E39.8068151 } \\
\text { N68.3883793 }\end{array}$ & 846 & 30 & $15 / 10$ & 0.5 \\
\hline Pop 6 & $\begin{array}{c}\text { Chimgan Mountain, Pangu river bank, } \\
\text { Tashkent province. }\end{array}$ & $\begin{array}{l}\text { N41.439897 } \\
\text { E70.0131223 }\end{array}$ & 824 & $30-40$ & $15 / 10$ & 0.375 \\
\hline
\end{tabular}


considered central range populations, whereas population from Tashkent province were more distinct and peripheral. Healthy leaves were placed into paper bags with small amount of silica gel. DNA extraction was conducted by DNAeasy Plant Mini Kit (Qiagen, Hilden, Germany) and checked by electrophoresis in $1.3 \%$ agarose gel, stained with ethidium bromide and run with DNA Ladder (Thermo Scientific, Waltham, MA, USA). Concentration and quality of DNA were checked with Nanodrop 2000 (Thermo Scientific).

\section{DNA isolation and ISSR-PCR amplification}

DNA samples of sufficient quality and with high concentration were used in this study. Six natural populations of $P$. fedtschenkoi were used and 101 primers were screened (Biotechnology Laboratory, University of British Columbia). From these, ten primers were selected which provided clear and polymorphic bands within all populations. The PCR reaction consisted of $4 \mu \mathrm{L}$ of DNA $(50 \mathrm{ng} / \mu \mathrm{L}), 4 \mu \mathrm{L}$ primer (300 $\mathrm{nM}$ ), $2 \mu \mathrm{L}$ of BSA (bovine serum albumin, $0.00025 \%$ ), $2 \mu \mathrm{L}$ of $10 \times$ PCR reaction buffer $(1 \times), 2 \mu \mathrm{L}$ dNTP $(0.2 \mathrm{mM}$ dNTPs), 2 units of Taq polymerase (Biotherm, Genecreft, UK) and $5.8 \mu \mathrm{L}$ distilled water for a $20 \mu \mathrm{L}$ reaction. The amplification was as follows: denature at $94^{\circ} \mathrm{C}$ for $1 \mathrm{~min} 30 \mathrm{~s}$ followed by 35 cycles; denature at $94^{\circ} \mathrm{C}$ for $40 \mathrm{~s}$; annealing $50^{\circ} \mathrm{C}$ for $45 \mathrm{~s}$ and extension at $72^{\circ} \mathrm{C}$ for $1 \mathrm{~min} 30 \mathrm{~s}$; ending with final extension at $72^{\circ} \mathrm{C}$ for $5 \mathrm{~min}$. The PCR products were checked using gel electrophoresis in $1.3 \%$ agarose gel $(\mathrm{w} / \mathrm{v})$, with $1 \times$ TBE buffer $\mathrm{pH}$ 8.0. Bands were sized using DNA Ladder (Thermo Scientific) which was added as $4 \mu \mathrm{L}$ along with samples. Electrophoresis was run at $160 \mathrm{~V}, 120-140 \mathrm{~mA}$, during $2 \mathrm{~h} 30 \mathrm{~min}$. Gel was visualized under UV transilluminator using the gel documentation system (Bio-Rad, Hercules, CA, USA). Bands were considered, if they appeared repeatedly in samples run a minimum of three times.

\section{Genetic diversity and differentiation analysis}

ISSR fragments are dominant markers and calculated from each plant sample as present (1) or absent (0) for only welldefined bands. Within-population genetic diversity was assessed for each population as (1) percentage of polymorphic loci $P$; (2) observed number of alleles $N_{\mathrm{a}}$ and effective number of alleles $N_{\mathrm{e}}$ (Kimura and Crow, 1964); (3) geneticdiversity $H_{\mathrm{e}}$ of Nei (1973), or expected heterozygosity; (4) Shannon's information index (S.I.) (Lewontin, 1972) all implemented in POPGENE 1.32 software (Yeh et al., 1997).

Among population genetic diversity was assessed as (1) FStatistics: Nei's (1973) $G_{\mathrm{st}}$ of population structure; (2) gene flow $\mathrm{Nm}$ from the estimate of $G_{\text {st }}$ (McDermott and McDonald,
1993); (3) genetic distance: Nei's (1972) genetic distance sand genetic identity between populations all implemented in POPGENE 1.32 software (Yehetal., 1997); (4) dendrogram based on Nei's (1972) genetic distances using an unweighte dpair-group method arithmetic average (UPGMA) topology modified from NEIGHBOR procedure of PHYLIP 3.5 by Joe Felsenstein with 1,000 permutations (POPGENE 3.1).

Analyses of molecular variance (AMOVA) were performed to study the partitioning of genetic variation within and among P. fedtschenkoi populations using AMOVA with 999 permutations in GenAlEx 6.2 (Peakall and Smouse, 2012). Bands were analyzed using the Euclidean distance matrix as per Excoffier et al. (1992). The principle coordinates analysis (PCA) was performed in GenAlEx 6.2 via covariance matrix with data standardization on the basis of pairwise population matrix of Nei's genetic distance (1973).

In order to test for a correlation between genetic distances $\left(G_{\mathrm{st}}\right)$ and geographical distances $(\mathrm{km})$ among populations, a Mantel test was performed using the program GenAlEx 6.2 (Peakall and Smouse, 2012) (computing 999 permutations).

\section{Hierarchical and model based cluster analysis}

Bayesian-based method Structure 2.3.3 was also applied to infer gene-pool structure in genetic data and to assume how many clusters, or genetic groups $(k)$ were most appropriate for interpreting the data. The original data matrices were imported into the Structure 2.3.3 program (Pritchard et al., 2000). The results of 10 runs for each value of $\Delta k$ were combined using algorithm CLUMPP with the length burn-in period of 50,000 at 50,000 Markov chain Monte Carlo (MCMC) repetitions without prior information on sampling location and phenotype data and assuming correlated allele frequencies and admixture ancestry model. The summary for each value of $\Delta k$ were displayed graphically. The mean membership proportion of each individual described the likelihood of that individual belonging to the respective clusters. The color coding output was used to show the assignments of individuals in each population to the clusters. Two approaches were applied to determine the best $\Delta k$ with STRUCTURE HARVESTER (Earl and vonHoldt, 2012): (1) following the recommendations by Evanno et al. (2005), the ad hoc statistic $\Delta k$ were calculated based on the rate of change in the log likelihood of data between consecutive $k$ values and (2) following the recommendations of Rosenberg et al. (2001) with use $L(K)=$ Ln $P(D)$. Mean $F_{\text {st }}$ values for each cluster were calculated on the bases of pairwise calculation of $\operatorname{Ln} P(D)$ for population.

Population structure was investigated by HICKORY 1.1 (Holsinger et al., 2002; Holsinger and Lewis, 2003). HICKORY 
1.1 allowed evaluating the departures from Hardy-Weinberg equilibrium in dominant as well as co-dominant markers. The ISSR data were fitted to four models: 'full model,' which allows for inbreeding, ' $\mathrm{f}=0$ ' model, which implies lack of inbreeding, 'theta $=0$ ' model, which implies a zero-valued $F_{\text {st }}$ analogue (i.e., no differentiation between populations), and 'ffree' model, which decouples the estimates of $\mathrm{f}$ andt heta. Default parameters were used incomputation: burn-in $=5000$, number of samples $=$ 25,000 , and thinning factor $=5$.

To estimate the best fit of the four models, the Deviance information criterion (DIC) (Spiegelhalter et al., 2002) was used with interpretations following the recommendations given in the manual. The posteriori distribution of the Theta II estimator (the estimate of $F_{\mathrm{st}}$ ) was numerically approximated through an MCMC.

\section{Results}

\section{Field work and conservation status assessment}

The EOO of $P$. fedtschenkoi estimated by using GeoCat Bridge 2.0 was $162,580,746 \mathrm{~km}^{2}$ based on published data (Fig. 1A), which is applicable to Least endangered according to IUCN Red List Categories and Criteria (version 3.1, 2012). The AOO was estimated at $56,000 \mathrm{~km}^{2}$ based on field work (Fig. 1B), addressing Endangered IUCN category.

\section{Genetic diversity and differentiation}

One hundred sixty-six amplified ISSR fragments (loci) were revealed from the 60 samples from 6 natural populations of $P$. fedtschenkoi with 10 markers: 164 loci were polymorphic and
2 loci were monomorphic (loci \#8 and 108). The number of amplified fragments varied depending on primer used, with the most informative primer being UBC857. Molecular weights of the bands vary from $300 \mathrm{bp}$ to $6,000 \mathrm{bp}$ (Fig. 2, Table 2).

The highest degree of genetic diversity occurred in population 2 from Surkhandarya province (Pop 2: $P=49.9$, $\left.N_{\mathrm{a}}=1.4940, N_{\mathrm{e}}=1.2714, H_{\mathrm{e}}=0.1613, A / L=82\right)$ while the diversity was lowest in population 6 from Tashkent province (Pop 6: $P=27.71, N_{\mathrm{a}}=1.2771, N_{\mathrm{e}}=1.1988, H_{\mathrm{e}}=0.110, A$ / $L=46)$ with a mean value $P=39.05, N_{\mathrm{a}}=1.40, N_{\mathrm{e}}=1.249$, $H_{\mathrm{e}}=0.143, A / L=67.66$ (Table 3). S.I. ranged from 0.1603 (population 6) to 0.2472 (population 5) with mean value 0.214 . Low value of gene flow $N_{m}=0.3954$ testified low gene exchange between populations resulting in differentiation between populations measured with mean value of Nei's $G_{\text {st }}=0.5584(1973)$.

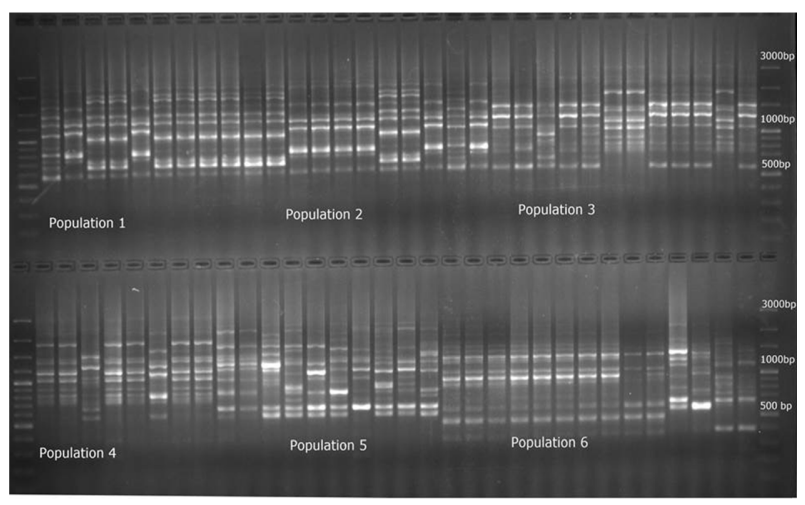

Fig. 2. An example of the molecular profile generated by primer UBC_ 811 for six populations of Prangos fedtschenkoi.

Table 2. ISSR (inter-simple sequence repeat) primer sequences, number of fragments scored and approximate size range (in base pairs) of the fragments resulted from each primer probing 60 samples from 6 populations of Prangos fedtschenkoi in Uzbekistan.

\begin{tabular}{|c|c|c|c|c|c|c|c|}
\hline \multirow{2}{*}{ No. } & \multirow{2}{*}{ Marker code } & \multirow{2}{*}{ Sequence $\left(5^{\prime}-3^{\prime}\right)$} & \multirow{2}{*}{$\begin{array}{c}\text { Annealing } \\
\text { temperature }\left({ }^{\circ} \mathrm{C}\right)\end{array}$} & \multirow{2}{*}{$\begin{array}{l}\text { Fragment size } \\
\text { range (bp) }\end{array}$} & \multicolumn{3}{|c|}{ Number of bands } \\
\hline & & & & & Polymorphic & Monomorphic & Total \\
\hline 1 & UBC_811 & $(\mathrm{GA})_{8} \mathrm{C}$ & 50 & $400-3,000$ & 17 & 1 & 18 \\
\hline 2 & UBC_818 & $(\mathrm{CA})_{8} \mathrm{G}$ & 52 & $800-6,000$ & 16 & 0 & 16 \\
\hline 3 & UBC_823 & $(\mathrm{TC})_{8} \mathrm{C}$ & 52 & $500-6,000$ & 20 & 0 & 20 \\
\hline 4 & UBC_825 & $(\mathrm{AC})_{8} \mathrm{~T}$ & 52 & $600-5,000$ & 14 & 1 & 15 \\
\hline 5 & UBC_840 & $(\mathrm{GA})_{8} \mathrm{YT}$ & 50 & $200-3,000$ & 17 & 0 & 17 \\
\hline 6 & UBC_855 & $(\mathrm{AC})_{8} \mathrm{YT}$ & 52 & $700-6,200$ & 19 & 0 & 19 \\
\hline 7 & UBC_857 & $(\mathrm{AC})_{8} \mathrm{YG}$ & 50 & $500-4,500$ & 22 & 0 & 22 \\
\hline 8 & UBC_ 880 & $(\mathrm{GGAGA})_{3}$ & 50 & $600-2,000$ & 8 & 0 & 8 \\
\hline 9 & UBC_881 & $(\text { GGGTG })_{5}$ & 56 & $300-3,000$ & 16 & 0 & 16 \\
\hline 10 & UBC_Mao & $(\mathrm{CTC})_{4} \mathrm{RC}$ & 50 & $700-4,000$ & 15 & 0 & 15 \\
\hline \multicolumn{3}{|c|}{ Total } & & & 164 & 2 & 166 \\
\hline
\end{tabular}


Table 3. Overall gene frequency summary of genetic variation statistics for all loci in POPGENE of six populations of Prangos fedtschenkoi in Uzbekistan (POPGENE 1.31).

\begin{tabular}{|c|c|c|c|c|c|c|c|c|}
\hline Variable & $\mathrm{N}$ & $P(\%)$ & $\mathrm{A} / \mathrm{L}$ & $\mathrm{n}_{\mathrm{a}}$ & $\mathrm{n}_{\mathrm{e}}$ & S.I. & $\mathrm{h}_{\mathrm{e}}$ & $\begin{array}{l}\text { Observed no. } \\
\text { of genotype }\end{array}$ \\
\hline Pop 1 & 10 & 42.17 & 70 & 1.4217 & 1.2626 & 0.2218 & 0.1495 & 8 \\
\hline Pop 2 & 10 & 49.9 & 82 & 1.4940 & 1.2714 & 0.2443 & 0.1613 & 10 \\
\hline Pop 3 & 10 & 34.44 & 57 & 1.3434 & 1.2099 & 0.1806 & 0.1210 & 10 \\
\hline Pop 4 & 10 & 43.37 & 72 & 1.4337 & 1.2766 & 0.2298 & 0.1554 & 10 \\
\hline Pop 5 & 10 & 47.59 & 79 & 1.4759 & 1.2785 & 0.2472 & 0.1645 & 10 \\
\hline Pop 6 & 10 & 27.71 & 46 & 1.2771 & 1.1988 & 0.1603 & 0.110 & 8 \\
\hline Mean & 10 & 39.05 & 67.66 & 1.40 & 1.2490 & 0.2140 & 0.1430 & 9.3 \\
\hline Species level & 60 & 98.80 & 164 & 1.98 & 1.64 & 0.5044 & 0.335 & 56 \\
\hline $\begin{array}{c}\text { Species level } \\
\text { without pop } 6\end{array}$ & 50 & 93.37 & 155 & 1.9337 & 1.4925 & 0.4465 & 0.2934 & 46 \\
\hline
\end{tabular}

Mean $\mathrm{Nm}=0.3954\left(\mathrm{Nm}^{*}=0.5(1-\right.$ Gst $) /$ Gst $($ McDermott and McDonald, 1993). Mean Gst Nei (1973) $=0.5584$.

Observed no. of genotype was defined from GenAlEx 6.2.

$N$, number of individuals; $P$, percentage of polymorphic loc; $A$, number of alleles per loci; $n_{a}$, observed number of alleles; $n_{e}$, effective number of alleles; he, Nei's (1973) gene diversity; S.I., Shannon's Information index.

Table 4. Results of the analysis of molecular variance (AMOVA) for six populations of Prangos fedtschenkoi in Uzbekistan with GenAlEx 6.2 from 999 permutations.

\begin{tabular}{cccccc}
\hline \hline $\begin{array}{c}\text { Source of } \\
\text { variation }\end{array}$ & d.f. & $\begin{array}{c}\text { Sum of } \\
\text { squares }\end{array}$ & $\begin{array}{c}\text { Mean } \\
\text { square }\end{array}$ & $\begin{array}{c}\text { Variance } \\
\text { components }\end{array}$ & $\begin{array}{c}\text { Percentage of } \\
\text { variation }^{* *}\end{array}$ \\
\hline Among populations & 5 & $1,020.033$ & 204.007 & 19.199 & 62 \\
Within populations & 54 & 648.800 & 12.015 & 12.015 & 38 \\
Total & 59 & $1,668.833$ & & 31.214 & 100 \\
\hline
\end{tabular}

$\mathrm{p} \leq 0.01$

Principal Coordinates

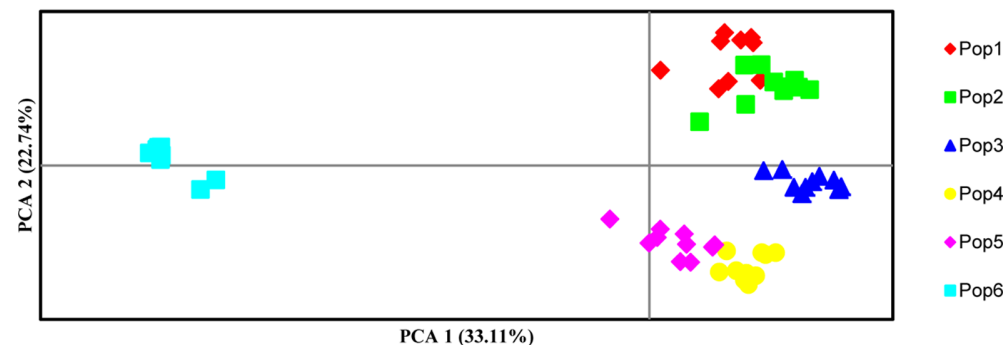

Fig. 3. Principle coordinates analysis (PCA) performed in GenAlEx 6.2 via covariance matrix with data standardization on the basis of Nei's genetic distance (Nei, 1973).

To assess the overall distribution of diversity within and among these populations, an AMOVA analysis was completed. The AMOVA revealed that there were highly significant $(\mathrm{p}<$ $0.01)$ genetic differences among the six populations of $P$. fedtschenkoi. Of the total genetic diversity, $62 \%$ of the variance occurred among populations and $38 \%$ occurred among individuals within populations (Table 4). Thus, AMOVA also supported the results of Nei's genetic statistics and Shannon's diversity estimation of a high degree of differentiation among populations.

The PCA defined strong partition of population 6 from the remainder of populations (Fig. 3). The first three PC axes accounted for $33.11 \%, 22.74 \%$, and $16.05 \%$, respectively, of the total variance. The most of populations gathered within the first two coordinate axes, accounted for $55.85 \%$ of the total variance in the data. PCA proved the differentiation into four 


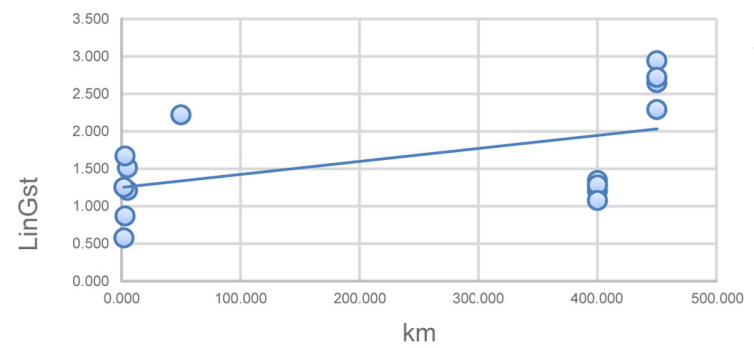

A

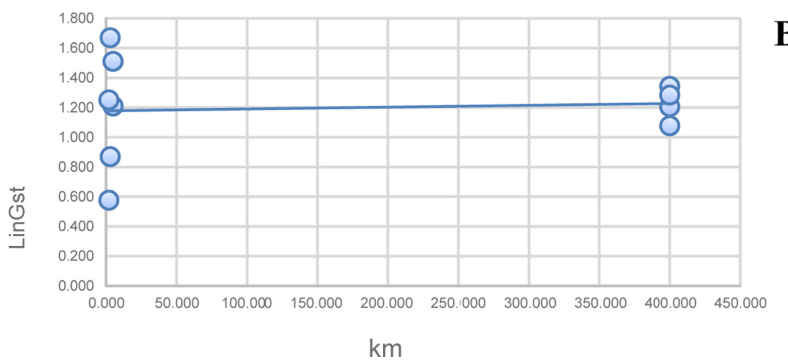

Fig. 4. A. Correlation between geographic remoteness and genetic distance (Nei, 1972) calculated in GenAlEx 6.2 for populations $1-6 . \mathrm{R}^{2}=$ 0.5137 and $\mathrm{p} \leq 0.005$ from 999 permutations. B. Correlation between geographic remoteness and genetic distance (Nei, 1972) calculated in GenAlEx 6.2 for populations $1-5 . \mathrm{R}^{2}=0.0787$ and $\mathrm{p}=0.6$ from 999 permutations.

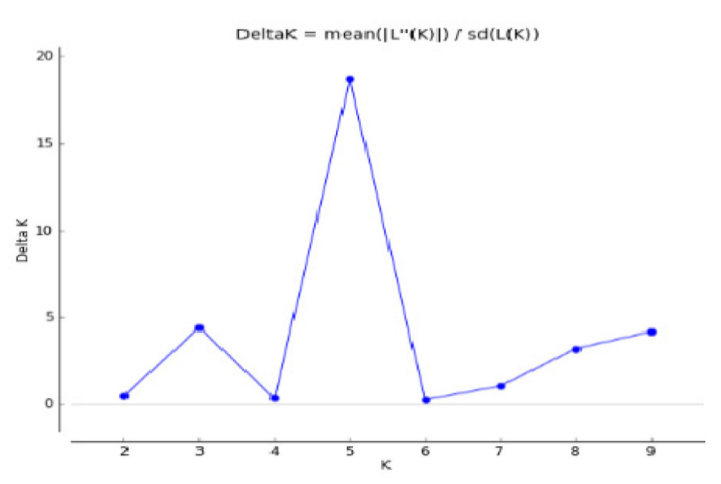

A

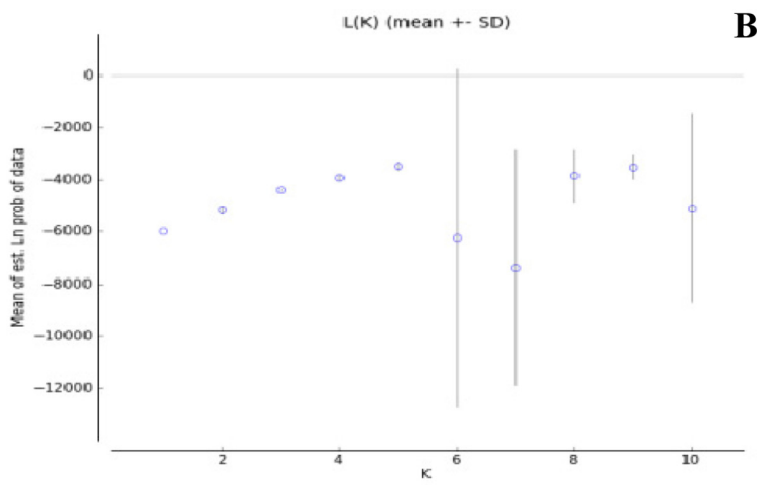

Fig. 5. Graphical display of best $\Delta \mathrm{k}$ result determined with Structure Harvester (Earl and vonHoldt, 2012): ad hoc statistic $\Delta \mathrm{k}$ was calculated based on the rate of change in the log likelihood of data between consecutive k values (Evanno et al., 2005) (A) and with use $L(K)=\operatorname{Ln} P(D)$ (Rosenberg et al., 2001) (B).

major clusters: cluster 1 contained populations 1 and 2, while cluster 2 contained genotype of population 3 , cluster 3 contained population 4 and 5 and population 6 represented apart in a fourth cluster.

Significant correlation between Nei's genetic distances (1972) and geographical distances between populations using the Mantel test was defined for all populations $(\mathrm{R}=0.5137, \mathrm{p} \leq$ 0.005) (Fig. 4A), testifying increase of genetic differentiation with geographic remoteness. But no correlation was found in analyses with exception of the most remote population 6 from the Mantel test $(\mathrm{R}=0.0787, \mathrm{p}=0.6)$ (Fig. $4 \mathrm{~B})$.

\section{Hierarchical and model-based cluster analysis}

The Bayesian model used in Structure 2.3.3 determined the best $\Delta k$ was 5 clusters, or genetic groups (Fig. $5 \mathrm{~A}, \mathrm{~B}$ ). The decision was made based on statistic $k$, which corresponded to the highest peak of this modal value appropriate to the number of clusters (genetic groups).

The model based clustering into five genetic groups corresponded to distance based clustering with UPGMA, which grouped populations 1 and 2 with population 3 , populations 4 and 5 grouped together in one cluster and population 6 represented apart in a fifth cluster (Fig. 6A, B). Both model-based (Structure 2.3.3) and distance-based (UPGMA, PCA) clustering analysis demonstrated similar patterns of populations combination into clusters and separation of population 6 from Tashkent province into genetically distinct group, confined with Mantel test as the result of geographic remoteness.

Overall proportion of membership of the samples in each of 5 clusters was examined more closely with Structure 2.3.3 based on 166 loci depicted in multiple lines for 60 individuals (Table 5). High degree of inter-population genetic differentiation was observed in this plot. But some members of these populations contained alleles from the other populations (differently colored segments). For example, members of Surkhandarya population contained alleles (colored segments) from both Jizzakh and Tashkent populations. However, most samples had the highest share of membership and lowest value of $F_{\text {st }}$ with in cluster 2, which included, presumably, populations 1-3 from Surkhandarya province (green in Fig. 7) and the lowest membership proportion and highest $F_{\text {st }}$ observed for cluster 3 (pink) which 
A

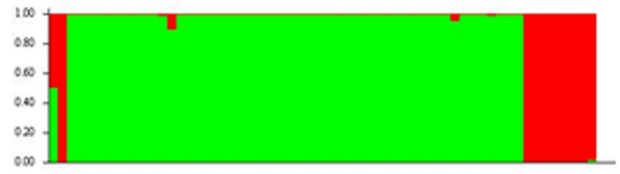

$\Delta k=2$

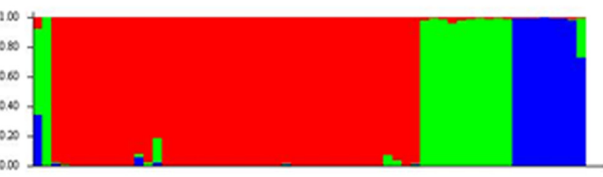

$\Delta k=3$

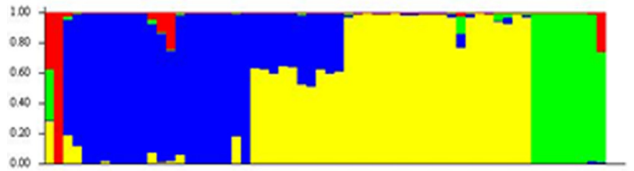

$\Delta k=4$
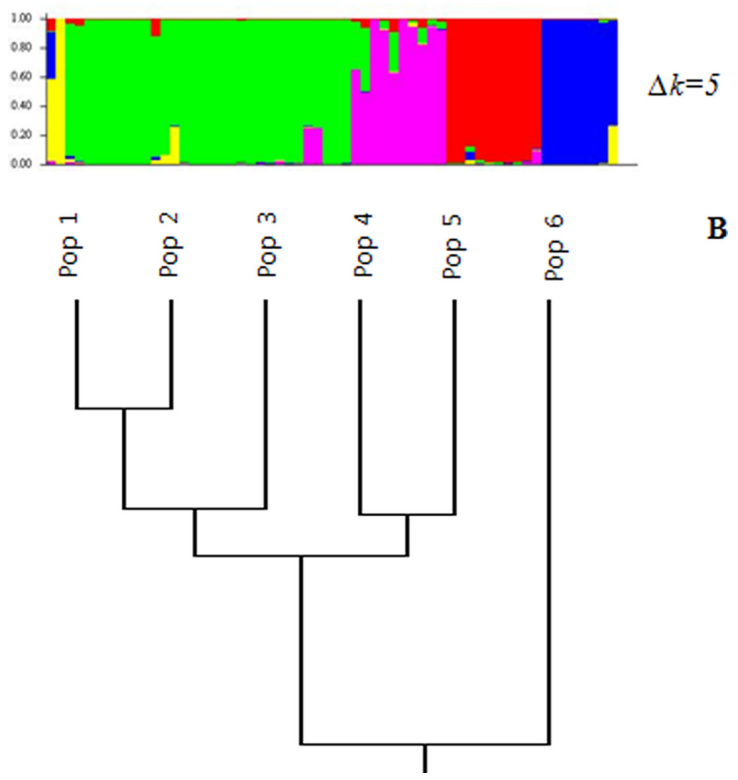

Fig. 6. A. Results of Structure 2.3 .3 analyses for Prangos fedtschenkoi based on 166 loci obtained with 10 inter-simple sequence repeat dominant markers. $\Delta \mathrm{k}=2,3,4$, and 5 depicted in single line. B. Dendrogram based Nei's (1972) genetic distance between populations of $P$. fedtschenkoi calculated with unweighted pair-group method arithmetic average. presented mostly population 4 . The order of samples in a line was presented from population 1 to 6 .

Another Bayesian genetic structure analysis of $P$. fedtschenkoi with Hickory 1.1 identified full model with Theta $\mathrm{II}=0.57$ and $\mathrm{f}=0.46$ as best model which was represented with the lowest DIC (DIC $=2026.89$ ). The second best was $\mathrm{f}$ $=0(\mathrm{DIC}=2077.61)$ with Theta II $=0.52$. In both cases Theta II values were lower than the $F_{\text {st }}$ presented by AMOVA, though

Table 5. Description of the clusters (genetic groups) resulted from Structure 2.3.3 analyses for Prangos fedtschenkoi based on 166 loci obtained with 10 markers.

\begin{tabular}{lccc}
\hline \hline Cluster & $\begin{array}{c}\text { Overall } \\
\text { proportion of } \\
\text { membership of } \\
\text { the samples in } \\
\text { each of 5 } \\
\text { clusters }\end{array}$ & $\begin{array}{c}\text { Mean } \\
\text { value } \\
\text { of } F_{\text {st }}\end{array}$ & $\begin{array}{c}\text { Average } \\
\text { distance } \\
\text { (expected } \\
\text { heterozygosity) } \\
\text { between } \\
\text { individuals in } \\
\text { the same cluster }\end{array}$ \\
\hline Cluster 1: yellow & 0.072 & 0.8703 & 0.0725 \\
Cluster 2: green & 0.578 & 0.0020 & 0.5786 \\
Cluster 3: pink & 0.015 & 0.9692 & 0.0150 \\
Cluster 4: red & 0.233 & 0.6333 & 0.2333 \\
Cluster 5: blue & 0.171 & 0.6954 & 0.1728 \\
\hline
\end{tabular}

$\Delta \mathrm{k}=5$.

Table 6. Genetic structure analysis with Hickory 1.1.

\begin{tabular}{cccc}
\hline \hline Model & DIC & $\mathrm{f}$ & Theta II \\
\hline Full & $2,026.89$ & 0.46 & 0.57 \\
$\mathrm{f}=0$ & $2,077.61$ & 0 & 0.52 \\
Theta II & $7,316.72$ & 0.95 & 0 \\
f free & $2,122.41$ & 0.5 & 0.58 \\
\hline
\end{tabular}

Default values for computations were used as follows: Burn-in = 5000 , sample $=25,000$, thinning factor $=5$. DIC, deviance information criterion.

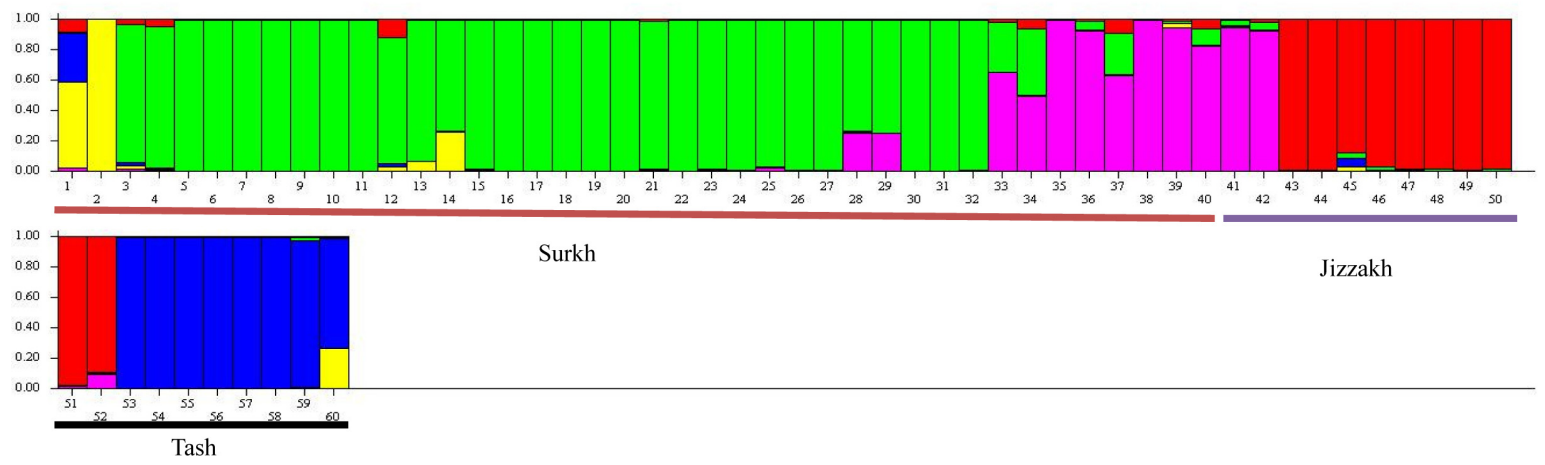

Fig. 7. Results of Structure 2.3.3 analyses for Prangos fedtschenkoi based on 166 loci obtained with 10 markers. $\Delta \mathrm{k}=5$ depicted in multiple lines for 60 individuals. Surkh, Surkhandarya province; Jizzakh, Jizzakh province; Tash, Tashkent province. 
all the $F_{\text {st }}$ analogues defined outstanding population differentiation. The f-free model presents $\mathrm{f}=0.50$ and Theta II $=0.58$, close result for Theta II was presented by the full model and DIC $=2122.41$. The worst model of all was Theta $\mathrm{II}=0$ resulting in $\mathrm{f}=0.95$ and $\mathrm{DIC}=7316.72$ (Table 6).

\section{Discussion}

\section{Genetic diversity and differentiation}

As expected from the recent expedition data, P. fedtschenkoi showed high level of differentiation caused from fragmentation of the distribution areas as the result of anthropogenic impact on habitat. Although neither recent nor reliable census is available for all several populations of P. fedtschenkoi remained in Kyrgyz Republic and Tajikistan, they are considered rare and dispersed species, probably, declining. Thus, high inbreeding process would have decreased within population genetic diversity deteriorated by low gene flow. But comparatively good level of polymorphism within populations suggests that historical gene flow took place among populations as their habitats were more integral on the territory of Uzbekistan.

ISSR markers were found to be highly polymorphic in $P$. fedtschenkoi with $98.8 \%$ of the loci showing variation at the species level as a whole and within the range $34.44 \%-55.9 \%$ in each population with the lowest records for population 6 , $27.71 \%$. For $P$. fedtschenkoi populations, the use of 10 ISSR markers detected 164 polymorphic and only two monomorphic loci. Levels of genetic variation within populations established for P. fedtschenkoi can be compared with other plants with similar life histories. ISSR markers generated 196 discernible DNA fragments with $166(84.7 \%)$ being polymorphic, indicating considerable genetic variation at the species level for some Apiaceae species (Qiu et al., 2004).

In spite of belonging to such a diversified family as Apiaceae, P. fedtschenkoi has never undergone population analysis using DNA molecular markers. Different approaches were used to research genetic diversity in an extremely narrow and wide spread species, allowing to compare them with present study data. Endemic for mountainous Middle Asia, $P$. fedtschenkoi populations revealed higher mean diversity parameters of variety potential $\left(P=39.05 \%, N_{\mathrm{a}}=1.40\right.$, $\left.H_{\mathrm{e}}=0.1430\right)$ than those expected for extremely narrow endemics $\left(P=16.1 \%, H_{e}=0.057\right)$ (López-Pujoletal., 2013) and endemic species $\left(P=26.3 \%, N_{\mathrm{a}}=1.39, H_{\mathrm{e}}=0.063\right)$ (Hamrick and Godt, 1989), but lowest for peripheral population 6 of $P$. fedtschenkoi among all other populations $(P=27.72 \%$, $\left.N_{\mathrm{a}}=1.19, H_{\mathrm{e}}=0.110\right)$.
Though, populations of $P$. fedtschenkoi in Uzbekistan are highly structured and differentiated, despite higher genetic variation within populations (AMOVA $F_{\text {st }}=0.62$ in GenAlEx 6.2; Theta II $=0.57964$ in Hickory $1.1 ; G_{\text {st }}=0.5584$ in POPGENE 1.32). Most of the variation in P. fedtschenkoi is distributed among populations (62\%) than within them (38\%).

Genetic structure of populations under study was considered with Structure software. The highest estimate of the likelihood for the division of data was achieved with $\Delta k=5$, i.e., five well defined clusters (genetic groups). The assignment of individuals to the clusters demonstrates that the most widespread pattern included $57 \%$ of samples, representing three geographically closest populations (Pop 1-3). The most restricted cluster included $17.1 \%$ of samples representing population 6 and partially population 5. Considerable differentiation of population 6 resulted from geographic remoteness as in accordance to the Mantel test $(\mathrm{R}=0.5137$, $\mathrm{p} \leq 0.005)$.

Since ISSR markers are dominant, expected heterozygosity $\left(H_{\mathrm{e}}\right)$ were calculated assuming Hardy-Weinberg equilibrium and it ranged between 0.11 (Pop 6) to 0.16 (Pop 5) with mean data 0.14 which in concordance with data for some of Apiaceae representatives ranging of expected heterozygosity from 0.11 to 0.13 (Qiu et al., 2004). Results revealed constancy in data within populations $1-5$ for most parameters, sharing similar values for polymorphic loci, observed and effective number of alleles, and Shannon's Index.

The value of Shannon's diversity index increases both when the number of genotypes, evenness and richness of features distribution increase and estimates within population genetic diversity. In our study, genetic diversity and evenness of its distribution among populations depleted within populations at the periphery of the species range in relation to central populations. Excluding data of this remote population from analysis inconsiderably decreased polymorphism and diversity data at the species level as well as evenness of features distribution within populations.

Data obtained through Hickory 1.1 of P. fedtschenkoi populations gave additional insights into population differentiation and gene flow. The DIC parameter is lower in the full model than in the $\mathrm{f}=0$ model (difference in DIC value $=50.72$ ), hence the $\mathrm{f}=0$ model (inbreeding equals zero) is least as likely as the full model, according to the Hickory 1.1 manual (Holsinger and Lewis, 2003). These results showed occurrence of inbreeding processes in the populations intensifying by low gene flow among them (mean $\mathrm{Nm}=$ 0.3954).

Obviously central populations are more plentiful in genetic 
diversity as distributed in geographical center and more adapted to its condition with the populations becoming smaller and more spatially isolated towards the range limits (Brussard, 1984; Lawton, 1993; Vucetich and Waite, 2003). In our study genetic diversity and evenness of its distribution among populations support 'central-peripheral' model in which genetic diversity supposed to be depleted within populations at the periphery of the species range in relation to central populations (Barrett and Husband, 1990; Hampe and Petit, 2005). But in other hand, if peripheral populations pose strong gene diversity and their differentiation from central population, which is adaptive direction due to different selective processes and reduced gene flow (Lenormand, 2002). Marginal populations may also promote shifts in species' geographical distributions in response to rapid climate change (Etterson and Shaw, 2001; Parmesan, 2006). The present close relationships among populations less than $250 \mathrm{~km}$ distant may reflect historical gene flow between P. fedtschenkoi populations rather than current situation. While, the high differentiation of population 6 could result from modern causes like anthropogenic impact and shift in distribution area might be response to climatic changes in the region.

Our results have a number of implications for the development of conservation strategies for P. fedtschenkoi. The detection of population differentiation using techniques such as ISSR may assist in the definition of appropriate units for conservation, thus providing a proper focus for conservation management or monitoring. In P. fedtschenkoi, the two main populations detected within Uzbekistan may be worth conservation attention. Undoubtedly, all local populations should be used for reintroduction as they are highly differentiated, but populations 2 and 5 appear to be particularly diverse and should perhaps be accorded highest priority for conservation. The definition of such management units will also be of value for informing the sampling for ex situ conservation activities and for sourcing material for restoring degraded populations of the species. To avoid inbreeding impact, the sources of outside from Uzbekistan populations might be considered as a valuable material to increase infra population diversity. Population 6 is worth to be included into conservation program as distinct and possible possessing valuable genetic features which caused or allowed surviving in new climatic and environmental conditions.

The results of our study also demonstrate that P. fedtschenkoi individuals could be uniquely identified based on ISSR. Finally, this study highlights the importance of molecular analysis in understanding the genetic systems governing natural populations and contributes to the knowledge of conservation of genetic resources in Uzbekistan flora.

\section{Conservation status}

Considerable decline of $P$. fedtschenkoi populations has been observed in recent years and mainly resulting from human activities such as agriculture, overgrazing and construction works. Uzbekistan is probably the most vulnerable of the Central Asian countries regarding water resources and irrigated agriculture as it has the largest irrigated area (4.3 million ha), the largest rural population (more than 14 million) and the highest population density $\left(75,8\right.$ pers $\left./ \mathrm{km}^{2}\right)$ (State Committee of RUzon Statistics, 2016). Uzbekistan ranks fifth among 90 cotton-growing countries ( $6 \%$ of the global cotton production) and is the second-largest cotton exporter in the world (FAO,2011). Though, the human-induced land degradation occurs mainly due to overexploitation of land resources for cropping and livestock farming, including irrigation practices and overgrazing (Adeel et al., 2005). Distribution areas of $P$. fedtschenkoi populations lie in remote regions separated by huge arable lands occupied with agricultural crops presently undergoing accelerated land degradation (CACILM, 2006; Limin, 2012). P. fedtschenkoi is assessed with GeoCat Bridge 2.0 as Endangered (EN) according to its Geographic Ranges based on published data, geo-referenced herbarium material and the results from field work.

\section{Conservation implications}

1. Seed collection, ex situ conservation and restoration or reintroduction

Seeds from all populations should be collected and used in ex situ conservation, restoration and reintroduction activities as this study results proved higher differentiation among populations of $P$. fedtschenkoi than between them. In order to capture all genetic diversity, even distinct populations should be covered as possessing unique genetic features which allowed or conditioned surviving of this species in the new climate conditions. Populations from outside of Uzbekistan are to be used as additional genetic source to avoid inbreeding which was defined in this study as main reason of low genetic diversity within populations of $P$. fedtschenkoi. As the populations are highly disrupted caused by anthropogenic impact, re-establishing connecting populations are advisable in the areas of its historical distribution to create corridors for gene flow between existing populations. Connecting populations should be re-established with participation of the seeds of all available populations as well as from outside of the country.

2. Management of existing, restored and reintroduced populations

Species based management and conservation is essential to 
ensure the protection of the limited remaining number of individuals in existing populations. Restoration of the existing populations and reintroduction in historical distribution areas should be accompanied with appropriate management and action plants with including monitoring of the individuals within the sites as well as genetic studying of these populations. The populations size and study their dynamics are to be continuously estimated. Restriction of agriculture activities and significant overgrazing in the areas of its distribution are definitely key activity to restore populations of this useful and endemic species.

\section{Acknowledgments}

Researches have been conducted in the frame of "Central Asia Green Road" project between Korea National Arboretum of Korea Forest Service (Republic of Korea) and Institute of Gene Pool of Plants and Animals of Uzbek Academy of Sciences (Republic of Uzbekistan).

\section{Literature Cited}

Adeel, Z., U. Safriel, D. Niemeijer, R. White, G. de Kalbermatten, M. Glantz, B. Salem, B. Scholes, M. Niamir-Fuller, S. Ehui and V. Yapi-Gnaore. 2005. Ecosystems and Human Wellbeing: Desertification Synthesis. A Report of the Millennium Ecosystem Assessment. World Resources Institute. Island Press, Washington, DC, 36 pp.

Barrett, S. C. H. and B. C. Husband. 1990. The genetics of plant migration and colonization. In Plant Population Genetics, Breeding and Genetic Resources. Brown, A. H. D., M. T. Clegg, A. L. Kahler and B. S. Weir (eds.), Sinauer Associates, Sunderland, MA. Pp. 254-277.

Brussard, P. F. 1984. Geographic patterns and environmental gradients: the central-marginal model in Drosophila revisited. Annual Review of Ecology and Systematics 15: 25-64.

Central Asian Countries Initiative for Land Management (CACILM) Multicountry Partnership Framework Support Project. Retrieved on January, 2017, from https:// www.adb.org/projects.

Davis, P. H., R. R. Mill and K. Tan. 1988. Prangos Lindl. In Flora of Turkey and the East Aegean Islands (Suppl. 1). Vol. 10. Davis, P. H., R. R. Mill and K. Tan (eds.), Edinburg University Press, Edinburg. Pp. 151.

Duman, H. 2000. Prangos Lindl. In Flora of Turkey and the East Eagean Islands (Suppl. 2), Vol. 11. Gunder, A., N. Ozhatay, T. Ekim and K. H. C. Başer (eds.), Edinburg University Press, Edinburg. Pp. 141-142.

Duman, H. and M. F. Watson. 1999. Ekimia, a new genus of Umbel- liferae, and two new taxa of Prangos Lindl. (Umbelliferae) from southern Turkey. Edinburg Journal of Botany 56: 199-209.

Duran, A., M. Sağiroğlu and H. Duman. 2005. Prangos turcica (Apiaceae), a new species from South Anatolia, Turkey. Annales Botanici Fennici 42: 67-72.

Earl, D. A. and B. M. vonHoldt. 2012. STRUCTURE HARVESTER: a website and program for visualizing STRUCTURE output and implementing the Evanno method. Conservation Genetics Resources 4: 359-361.

Etterson, J. R. and R. G. Shaw. 2001. Constraint to adaptive evolution in response to global warming. Science 294: 151-154.

Evanno, G. S. Regnuat and J. Goudet. 2005. Detecting the number of clusters of individuals using the software structure: a simulation study. Molecular Ecology 14: 2611-2620.

Excoffier, L., P. E. Smouse and J. M. Quattro. 1992. Analysis of molecular variance inferred from metric distances among DNA haplotypes: application to human mitochondrial DNA restriction sites. Genetics 131: 479-491.

FAO, 2011. FAO Statistics Division. Retrieved on December, 2016, from http://faostat.fao.org.

GeoCat B.V. 2015. GeoCat Bridge 2.0: Extension for Esri ArcGIS Desktop. GeoCat B.V., Bennekom.

Hampe, A. and R. J. Petit. 2005. Conserving biodiversity under climate change: the rear edge matters. Ecology Letters 8: 461-467.

Hamrick, J. L. and M. J. W. Godt. 1989. Allozyme diversity in plant species. In Plant Population Genetics, Breeding and Genetic Resources. Brown A. H. D., M. T. Clegg, A. L. Kahler and B. S. Weir (eds.), Sinauer Associates, Sunderland, MA. Pp. 43-63.

Herrnstadt, I. and C. C. Heyn. 1977. A monographic study of the genus Prangos (Umbelliferae). Biossiera 26: 1-91.

Herrnstadt, I. and C. C. Heyn. 1987. Prangos Lindl. In Flora Iranica 162. Rechinger, H. K. (ed.), Akademische Druck und Verlagsanstalt, Graz. Pp. 190-206.

Holsinger, K. E. and P. O. Lewis. 2003. HICKORY: a package for analysis of population genetic data. V1.0. Retrieved on May, 2016, from http://www.eeb.uconn.edu.

Holsinger, K. E., P. O. Lewis and D. K. Dey. 2002. A Bayesian approach to inferring population structure with dominant markers. Molecular Ecology 11: 1157-1164.

International Union for Conservation of Nature and Natural Resources (IUCN). 2012. IUCN Red List Categories and Criteria: Version 3.1. 2nd ed. IUCN, Gland and Cambridge, $32 \mathrm{pp}$.

Kimura, M. and J. F. Crow. 1964. The number of alleles that can be maintained in a finite population. Genetics 49: 725-738.

Kljuykov, E. and U. Ukrainskaja. 2010. Distribution of the Umbelliferae in Middle Asia and Kazakhstan. Plant Diversity and Evolution 128: 547-559. 
Kuzmina, L. V. 1963. Central Asian species of Prangos Lindl. genera as the source of phytocoumarins. In Plants - the sources of biological active compounds with therapeutic effect. M-L.: Nazchsa: 5-27. (in Russian)

Kuznetsova, G. A. and L. M. Belenovskaya. 1969. Additional information on the coumarin composition of Prangos fedtschenkoi (Regel et Schmalh.) Korob., Prangos tschimganica Bergapten Fedtschenkoi, and Prangos isphairamica Bergapten Fedtschenkoi. (Umbelliferae). Journal of Applied Chemistry of the USSR 42: 471.

Lawton, J. H. 1993. Range, population abundance and conservation. Trends in Ecology and Evolution 8: 409-413.

Lenormand, T. 2002. Gene flow and the limits to natural selection. Trends in Ecology and Evolution 17: 183-189.

Lewontin, R. C. 1972. The apportionment of human diversity. In Evolutionary Biology. Vol. 6. Dobzhansky, T., M. K. Hecht and W. C. Steere (eds.), Springer, New York. Pp. 381-398.

Limin, H. Engaging with land users: the first steps on a long road. 2012. In Rangeland Stewardship in Central Asia: Balancing Improved Livelihoods, Biodiversity Conservation and Land Protection. Squires, V. R. (ed.), Springer, Dordrecht. Pp. 333-356.

López-Pujol, J., M. C. Martinell, S. Masso, C. Blanché and L. Sáez. 2013. The 'paradigm of extremes': extremely low genetic diversity in an extremely narrow endemic species, Coristospermum huteri (Umbelliferae). Plant Systematics and Evolution 299: 439-446.

Lyskov D. F. 2015. The systematics of the genera Prangos (Umbelliferae, Apioideae) and allied taxa: comparing of morpho-anatomical and molecular data. Ph.D. thesis. 217 pp. (in Russian)

McDermott, J. M. and B. A. McDonald. 1993. Gene flow in plant pathosystems. Annual Review of Phytopathology 31: 353-373.

Nei, M. 1972. Genetic distance between populations. The American Naturalist 106: 283-292.

Nei, M. 1973. Analysis of gene diversity in subdivided populations. Proceedings of the National Academy of Sciences of the United States of America 70: 3321-3323.

Parmesan, C. 2006. Ecological and evolutionary responses to recent climate change. Annual Review of Ecology, Evolution, and Systematics 37: 637-669.

Peakall, R. and P. E. Smouse. 2012. GenAlEx 6.2: genetic analysis in Excel. Population genetic software for teaching and research: an update. Bioinformatics 28: 2537-2539.

Pimenov, M. G. and V. N. Tikhomirov. 1983. The taxonomic problems in the genera Prangos Lindl., Cachrys L., Cryptodiscus Schrenk and Hippomarathrum Hoffmgg. et Link (Umbelliferae: Apioideae). Feddes Repertorium 94: 145-164.

Pimenov, M. G. and M. V. Leonov. 1993. The Genera of Umbel- liferae. Royal Botanic Gardens, Kew, 164 pp.

Pimenov, M. G., E. Akalin and E. Kljuykov. 2005. Prangos ilanae (Umbelliferae), a new species from Western Turkey. Candollea 60: 379-385.

Post, G. E. 1932. Flora of Syria, Palestine and Sinai. American Press, Beirut. Pp. 538-539.

Pritchard, J. K., M. Stephens and P. Donnelly. 2000. Inference of population structure using multilocus genotype data. Genetics 155: 945-959.

Qiu, Y.-X., D.-Y. Hong, C.-X. Fu and K. M. Cameron. 2004. Genetic variation in the endangered and endemic species Changium smyrnioides (Apiaceae). Biochemical Systematics and Ecology 32: 583-596.

Rosenberg, N. A., T. Burke, K. Elo, M. W. Feldman, P. J. Freidlin, M. A. Groenen, J. Hillel, A. Mäki-Tanila, M. Tixier-Boichard, A. Vignal, K. Wimmers and S. Weigend. 2001. Empirical evaluation of genetic clustering methods using multilocus genotypes from 20 chicken breeds. Genetics 159: 699-713.

Şenol, S. G., H. Yildırim and O. Seçmen. 2011. Prangos hulusii sp. nov. (Apiaceae) from West Anatolia, Turkey. Nordic Journal of Botany 29: 402-407.

Shishkin, B. K. 1950. Prangos Lindl. In Flora of the USSR. Vol. 16. Shishkin B. K. (ed.), AN SSSR, Moscow-Leningrad. Pp. 263-273

Spiegelhalter, D. J., N. G. Best, B. P. Carlin and A. van der Linde. 2002. Bayesian measures of model complexity and fit. Journal of the Royal Statistical Society: Series B (Statistical Methodology) 64: 583-639.

State Committee of RUz on Statistics. Retrieved on December, 2016, from http://www.stat.uz.

Tutin, T. G. 1968. Cachrys L. In Flora Europaea. Vol. 2.Tutin T. G., V. H. Heywood, N. A. Burges, D. M. Moore, D. H. Valentine, S. M. Walters and D. A. Webb (eds.), Cambridge University Press, Cambridge. Pp. 34-344.

Vucetich, J. A. and T. A. Waite. 2003. Spatial patters of demography and genetic processes across the species' range: null hypotheses for landscape conservation genetics. Conservation Genetics 4: 639-645.

Yeh, F. C. and T. J. B. Boyle, 1997. Popgene. Population genetic analysis of co-dominant and dominant markers and quantitative traits. Belgian Journal of Botany 129: 157.

Zakirov, K. Z. 1961. The flora and vegetation of the ZeravshanRiver Basin. Part 2. Conspectus of the flora. Akademii Nauk Uzbekskoi SSR, Tashkent. Pp. 1, 2.

Zietkiewicz, E., A. Rafalski and D. Labuda. 1994. Genome fingerprinting by simple sequence repeat (SSR)-anchored polymerase chain reaction amplification. Genomics 20: 176-183. 